\title{
Clicking DNA to gold nanoparticles: poly-adenine-mediated formation of monovalent DNA-gold nanoparticle conjugates with nearly quantitative yield
}

\author{
Guangbao Yao ${ }^{1,2,4}$, Hao Pei ${ }^{2,4}$, Jiang $\mathrm{Li}^{2,4}$, Yun Zhao ${ }^{1}$, Dan $\mathrm{Zhu}^{2}$, Yinan Zhang ${ }^{2}$, Yunfeng Lin ${ }^{3}$, Qing Huang ${ }^{2}$ \\ and Chunhai Fan ${ }^{2}$
}

\begin{abstract}
Monovalent DNA-gold nanoparticle (mDNA-AuNP) conjugates hold great promise for widespread applications, especially the construction of well-defined, molecule-like nanosystems. Previously reported methods all rely on the use of thiolated DNA to functionalize AuNPs, resulting in relatively low yields. Here, we report a facile method to rapidly prepare mDNA-AuNPs using a poly-adenine (polyA)-mediated approach. As polyA can selectively bind to AuNPs with high controllability of the surface density of DNA, we can use a DNA strand with a sufficiently long polyA to wrap around the surface of an individual AuNP, preventing further the adsorption of additional strands. Based on this observation, we obtained mDNA-AuNPs with a nearly quantitative yield of $\sim 90 \%$ using $80 \mathrm{As}$, as confirmed by both gel electrophoresis and transmission electron microscope observation. The yields of mDNA-AuNPs were insensitive to the stoichiometric ratio between DNA and AuNPs, suggesting the click chemistry-like nature of this polyA-mediated reaction. mDNA-AuNPs exhibited rapid kinetics and high efficiency for sequence-specific hybridization. More importantly, we demonstrated that AuNPs of fixed valences could form well-defined heterogenous oligomeric nanostructures with precise, atom-like control.
\end{abstract}

NPG Asia Materials (2015) 7, e159; doi:10.1038/am.2014.131; published online 30 January 2015

\section{INTRODUCTION}

Thiolated DNA functionalized gold nanoparticles (DNA-AuNPs) have been popularly used to develop new tools for numerous applications, including bioassays, bioimaging and nanomedicine. ${ }^{1-8}$ In a different line, DNA-AuNP conjugates hold great promise as the building blocks for bottom-up construction of functional nanosystems that exploits both the highly specific DNA base-pair interactions and the unique optical and electronic properties of AuNPs. ${ }^{9-13}$ During the past two decades, we have witnessed dramatic advances in such functional nanosystems, including the formation of molecule-like crystal structures and the assembly of dynamic nanodevices. ${ }^{14-18}$ Despite the rapid progress, most of these applications used polyvalent DNA-AuNP conjugates without knowing the exact number of loaded DNA strands. Although polyvalent DNA-AuNPs possess unique merits, such as signal amplification and cellular internalization; ${ }^{19-21}$ such inaccuracy may introduce potential imperfectness in the artificially constructed nanosystems.

There have been many efforts to develop DNA-AuNP conjugates of fixed valences, ${ }^{16,22,23}$ in particular, monovalent DNA-AuNPs (mDNAAuNPs, Figure 1a). ${ }^{4,9,10,24-33}$ In a straightforward approach, AuNPs are titrated with DNA of different ratios, and then, the resulting conjugates are purified using gel electrophoresis to obtain mDNA-AuNPs. ${ }^{10,24,32}$ The yield of this approach is usually very low. Improvement of the yield was realized using special chemical modification and/or double-stranded DNAs. ${ }^{30,33}$ More recently, Tang, Liu and coworkers reported a dual steric hindrance strategy for the synthesis of mDNA-AuNPs, which led to a remarkably high yield of $70 \% .{ }^{30}$ However, this method requires multiple steps and lacks generality.

In this work, we report a single-step and purification-free method for the preparation of mDNA-AuNPs with nearly quantitative yield by

\footnotetext{
${ }^{1}$ Key Laboratory of Bio-Resources and Eco-Environment, Ministry of Education, College of Life Science, Sichuan University, Chengdu, China; ${ }^{2}$ Division of Physical Biology \& Bioimaging Center, Shanghai Synchrotron Radiation Facility, CAS Key Laboratory of Interfacial Physics and Technology, Shanghai Institute of Applied Physics, Chinese Academy of Sciences, Shanghai, China and ${ }^{3}$ State Key Laboratory of Oral Diseases, West China Hospital of Stomatology, Sichuan University, Chengdu, China

${ }^{4}$ These authors contributed equally to this work.

Correspondence: Professor Y Zhao, Key Laboratory of Bio-Resources and Eco-Environment, Ministry of Education, College of Life Science, Sichuan University, Chengdu 610064, China. E-mail: zhaoyun@scu.edu.cn

or Professor Y Lin, State Key Laboratory of Oral Diseases, West China Hospital of Stomatology, Sichuan University, Chengdu 610041, China

E-mail: yunfenglin@scu.edu.cn

or Professor C Fan, Division of Physical Biology Biology \& Bioimaging Center, Shanghai Institute of Applied Physics, Chinese Academy of Sciences, P0 Box 800-204, Shanghai 201800, China. 
a

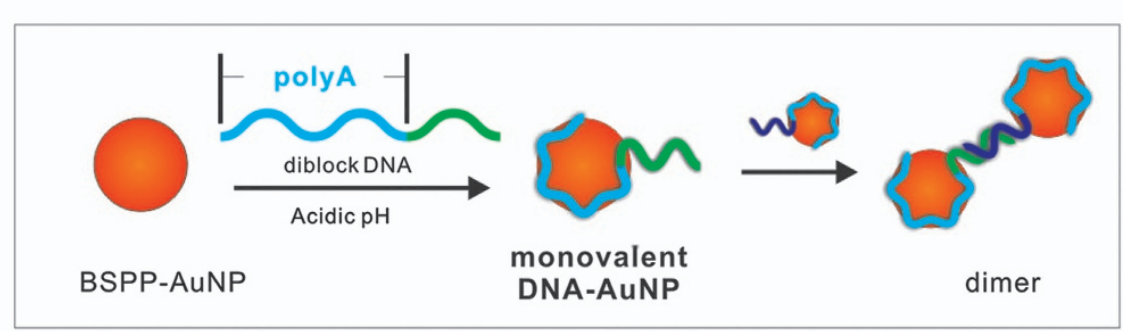

b

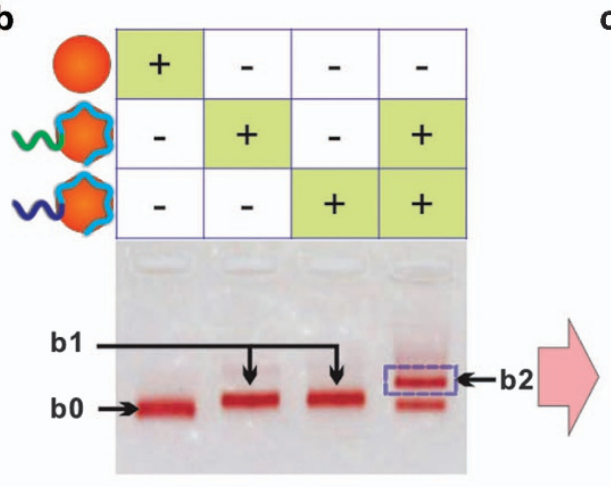

C

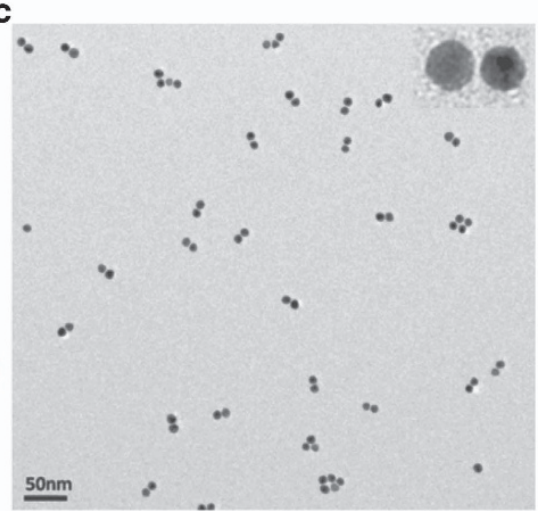

Figure 1 (a) Scheme showing polyA-mediated formation of mDNA-AuNPs. (b) Gel electrophoresis and (c) TEM characterization of mDNA-AuNPs and the dimer of two types of mDNA-AuNPs with complementary sequences. Inset: the magnified image of a dimer.

exploiting a conceptually new strategy of poly-adenine (polyA)mediated functionalization of AuNPs (Figure 1a). We previously found that unmodified diblock DNA strands bearing consecutive adenines could strongly bind to AuNPs with the polyA block, whereas the other block lifted up at the surface for sequence recognition. ${ }^{34}$ Significantly, polyA not only possesses similar affinity to the thiol group but also offers greater control of DNA assembly on AuNPs. The surface density of DNA can be facilely modulated by simply varying the length of polyA. ${ }^{34}$ Inspired by this study, we propose that a single AuNP can accommodate only one strand of DNA when the polyA length is sufficiently long.

\section{MATERIALS AND METHODS}

\section{Reagents and materials}

All oligonucleotides were synthesized and purified by Life Technologies Corp. (Shanghai, China), and the sequences are presented in Supplementary Table S1. Bis(p-sulfonatophenyl) phenylphosphine dihydrate dipotassium salt (BSPP) was from Sigma-Aldrich (St Louis, MO, USA). AuNPs of 5 or $10 \mathrm{~nm}$ were obtained from Ted Pella Inc. (Redding, CA, USA) Citrate-HCl buffers were prepared using the protocol reported in Pellegrino et al..$^{35}$

\section{Preparation of BSPP-protected AuNPs}

BSPP ( $3 \mathrm{mg}$ ) was added to a $10-\mathrm{ml}$ solution of AuNPs (10 or $5 \mathrm{~nm}$ ), and the mixture was shaken overnight at room temperature. $\mathrm{NaCl}$ was added slowly to this mixture while stirring until the color changed from deep burgundy to light purple. The resulting mixture was centrifuged at 8000 r.p.m. for $5 \mathrm{~min}$, and the supernatant was then removed. AuNPs were then resuspended in $0.5 \mathrm{ml}$ of BSPP solution $(2.5 \mathrm{~mm})$ and mixed with $0.5 \mathrm{ml}$ methanol. The mixture was again centrifuged, the supernatant was removed and the AuNPs were resuspended in $100 \mu \mathrm{l}$ of BSPP solution $(2.5 \mathrm{~mm})$. The concentration of the $\sim 100$-fold concentrated AuNPs was estimated from the optical absorbance at $520 \mathrm{~nm}$.

\section{PolyA-mediated synthesis of mDNA-AuNPs}

For preparing mDNA-AuNPs, $100 \mathrm{~nm}$ of BSPP-AuNPs was mixed with DNA strands with different polyA lengths (presented in Supplementary Table S1, for example, polyA80) of appropriate concentrations (typically $500 \mathrm{nm).} \mathrm{After} 1$ min, citrate- $\mathrm{HCl}$ buffer $(500 \mathrm{~mm}, \mathrm{pH} 3.1)$ was rapidly added to the DNA/ AuNPs mixture to a final citrate concentration of $10 \mathrm{~mm}$. This mixture was incubated for $15 \mathrm{~min}$ at room temperature. For preparing bivalent and trivalent DNA-AuNPs, the protocol was similar, except that a different polyA-DNA (typically polyA40-DNA) was chosen.

\section{Agarose gel electrophoresis separation and recovery of DNA- AuNPs}

Two percent agarose (Bio-Rad, (Hercules, CA, USA) dissolved with $0.5 \times \mathrm{TBE}$ buffer) was used for gel electrophoresis. Ten microliters of DNA-AuNP conjugates containing 50\% sucrose was added to each lane, and the gel was run at $100 \mathrm{~V}$ for at least $40 \mathrm{~min}$. The running buffer was also $0.5 \times \mathrm{TBE}$ buffer. The images of gels were recorded using a digital camera. To recover DNAAuNP after electrophoresis separation, we cut the desired band out from the gel and immersed it in an electro-elution buffer (30\% sucrose, $0.5 \times \mathrm{TBE})$. Subsequently, the red-colored products were recollected and then centrifuged (12 000 r.p.m., $30 \mathrm{~min}$ ) to remove the sucrose solution, which was subsequently resuspended in $0.05 \mathrm{~m}$ sodium phosphate buffer $(0.05 \mathrm{M} \mathrm{NaCl}, 5 \mathrm{~mm} \mathrm{~PB}, \mathrm{pH}$ 7.4). The yields of DNA-AuNPs were calculated by analyzing the color intensities of bands in gel via the software ImageJ.

\section{PolyA adsorption kinetics}

FAM-labeled polyA oligonucleotide (FAM-polyA, see Supplementary Table S1, $1 \mu \mathrm{M}$ ) was mixed with citrate-AuNPs or BSPP-AuNPs at either $\mathrm{pH} 7$ or $\mathrm{pH} 3$. The fluorescence intensity (FI) of FAM (emission at $515 \mathrm{~nm}$ ) at each timepoint was recorded by using a fluorescence spectrometer (F-4500, Hitachi, Tokyo, Japan) and was normalized to the initial FI (F0). In the case of acidic $\mathrm{pH}$, the resulting mixture was re-adjusted to neutral $\mathrm{pH}$ using $\mathrm{PBS}$ before performing the fluorescence measurement to avoid the effect of $\mathrm{pH}$ on the FAM fluorescence. 


\section{DNA hybridization}

PolyA-probe and SH-probe (Supplementary Table S1) were used for preparing mDNA-AuNPs and pDNA-AuNPs. pDNA-AuNPs were prepared by using a 'salt-aging' protocol, and the number of immobilized DNA strands was quantified by using a displacement-based fluorescent assay. ${ }^{36}$ Thiol-mediated mDNA-AuNPs were prepared using a strand displacement strategy. ${ }^{37} \mathrm{Next}$, FAM-labeled target DNA (Supplementary Table S1, $5 \mathrm{nM}$ ) was mixed with polyA mDNA-AuNPs ( $5 \mathrm{~nm}$ ), thiol mDNA-AuNPs(5 nm), or DABCYL-labeled free probe $(5 \mathrm{nM})$. The FI of FAM at each timepoint was recorded and was normalized to the initial fluorescence intensity (F0). The hybridization efficiencies were determined according to the previously reported protocol..$^{34}$ The FAM-labeled target DNA $(2 \mu \mathrm{M})$ was reacted with either polyA mDNAAuNPs ( $5 \mathrm{~nm}$ ) and thiol pDNA-AuNPs ( $5 \mathrm{~nm}$ ) under hybridization conditions $(0.1 \mathrm{M} \mathrm{NaCl}, 10 \mathrm{~mm}$ PB, pH 7.4) for $2 \mathrm{~h}$. Non-hybridized DNA strands were then removed via centrifugation (12000 r.p.m., $30 \mathrm{~min}$ ). Subsequently, the FAM-labeled DNA was dehybridized with addition of $\mathrm{NaOH}$ (final concentration $50 \mathrm{~mm}, \mathrm{pH} 11-12,2 \mathrm{~h}$ ). Finally, the dehybridized DNA was separated via centrifugation, neutralized by addition of $1 \mathrm{M} \mathrm{HCl}$, and then quantified with fluorescent measurement. The fluorescence intensities were converted to molar concentrations of the target DNA by interpolation from a standard linear calibration curve.

\section{Assembly of DNA-AuNPs}

DNA-AuNPs with complementary sequences (polyA80-DNA and polyA80cDNA in Supplementary Table S1) were mixed at a proper ratio (typically 1:1), and the concentration of $\mathrm{NaCl}$ was then increased to $100 \mathrm{~mm}$ by adding $1 \mathrm{M}$ sodium phosphate buffer $(1 \mathrm{M} \mathrm{NaCl}, 100 \mathrm{~mm} \mathrm{~PB}, \mathrm{pH}$ 7.4). The mixture was then annealed overnight.

\section{Transmission electron microscopy}

The sample solution $(5 \mu \mathrm{l})$ was deposited on the grid for $5 \mathrm{~min}$, after which, the excess solution was wicked away with filter paper. Imaging was performed using a Tecnai TF20 microscope (FEI, Hillsboro, OR, USA) operated at an acceleration voltage of $200 \mathrm{kV}$.

\section{RESULTS AND DISCUSSION}

The DNA strands used for functionalization of AuNPs contain a polyA block of various lengths and a block of designed sequences for DNA hybridization. $^{34}$ In our previous work, this diblock DNA was incubated with citrate-stabilized AuNPs of $10 \mathrm{~nm}$ using the 'salt-aging' protocol that lasts 1-2 days. ${ }^{3}$ Nevertheless, the protocol requires excessive amount of DNA strands to stabilize AuNPs against saltaging, which is not suitable for the preparation of mDNA-AuNPs because of the low-DNA/AuNP ratios. Indeed, we found that AuNPs easily aggregated in our experimental settings (DNA/AuNPs ratio $<20$, data not shown). To avoid this problem, we first stabilized AuNPs with BSPP, so that they were stable in solutions of high ionic strength. Importantly, polyA can effectively displace BSPP and bind to AuNPs. When the diblock DNA was incubated with BSPP-protected AuNPs, we found that the resultant conjugates were hybridizable with the complementary sequence, suggesting the successful formation of DNA-AuNP conjugates (Figure 1). Agarose gel electrophoresis was used to purify these conjugates. ${ }^{35}$ We observed a ladder of red-color bands in the gel that corresponded to the DNA-AuNP conjugates with different numbers of DNA strands. The red color arises from the plasmonic adsorption of 10-nm AuNPs at $519 \mathrm{~nm}$. Previous studies

a $\mathrm{pH}$ (for polyA80-DNA)
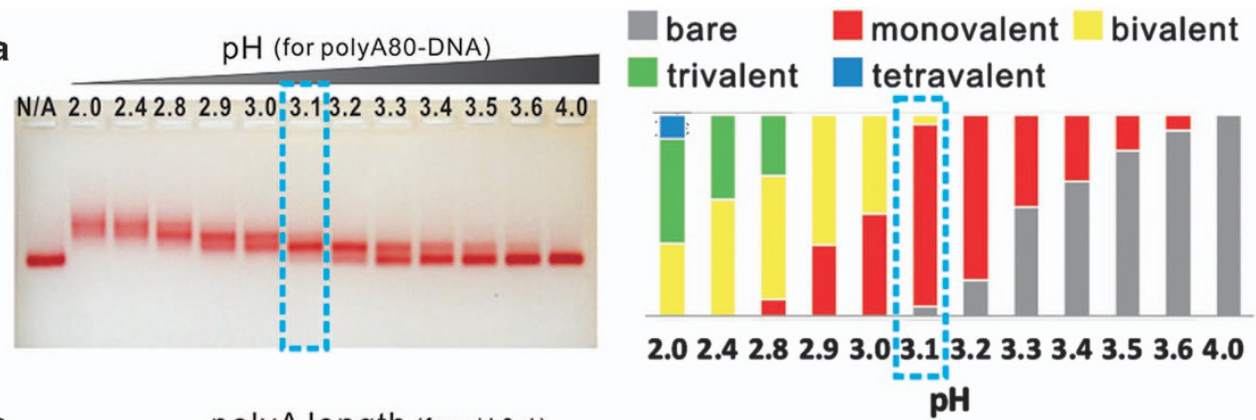

b polyA length (for $\mathrm{pH} 3.1$ )
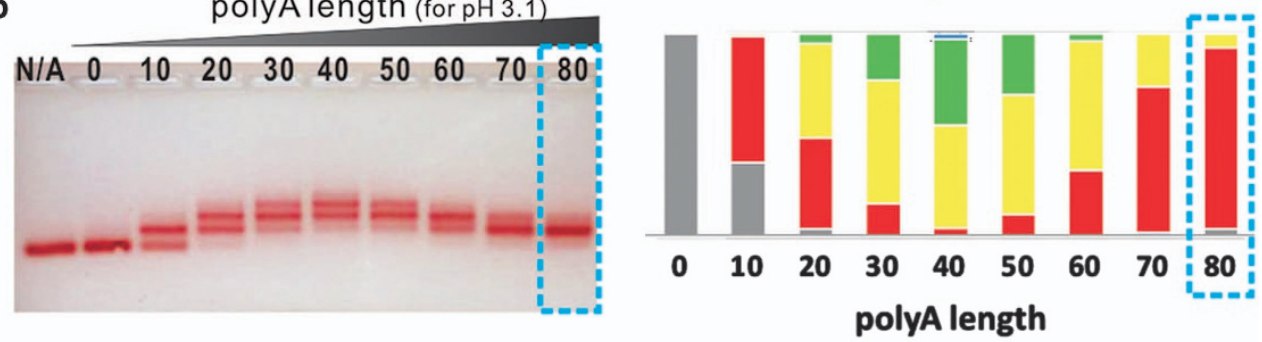

C
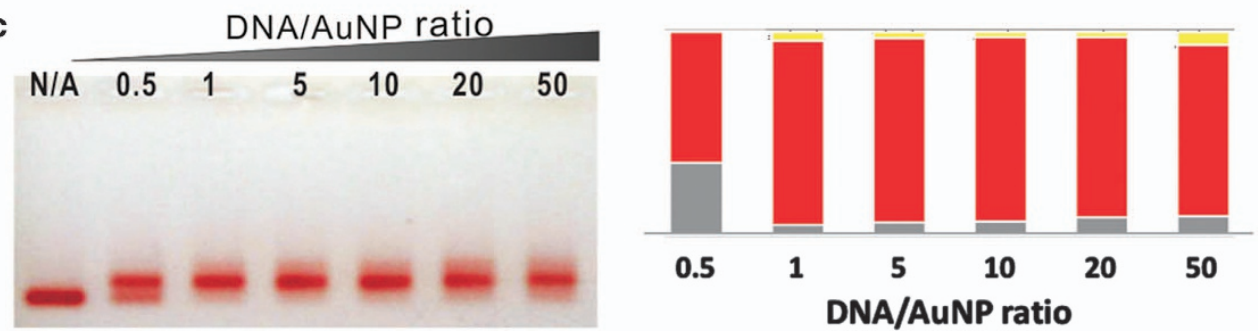

Figure 2 Gel images and the yields of different products from AuNPs treated with (a) polyA80-DNA under different pH conditions; (b) DNA strands of different polyA lengths; and (c) polyA80-DNA of different DNA/AuNPs ratios. 'N/A' denotes untreated BSPP-AuNPs. The dashed frame represents the highest yield of mDNA-AuNPs. 
have shown that the number of DNA strands on AuNPs is generally inversely related to their migration rate in gel electrophoresis. ${ }^{24,38} \mathrm{We}$ reasoned that the band (b1) located right above the band of nonfunctionalized AuNPs (b0) corresponded to mDNA-AuNPs, given that the migration of mDNA-AuNPs should be least retarded by the attached single DNA strand. The conjugate in b1 was recovered via electroelution. To confirm that this conjugate was mDNA-AuNPs, we performed a hybridization assay by using two types of mDNA-AuNPs that had complementary sequences in the recognition blocks. As shown in Figure 1b, the two mDNA-AuNPs exhibited single bands (b1) that migrated approximately the same distance in the gel, which were slightly slower than non-functionalized AuNPs (b0). After hybridization, gel electrophoresis indicated the presence of two bands, one at the position of $\mathrm{b} 1$ and the other with slower migration (b2). The recovered conjugates from b2 were characterized using a transmission electron microscope, which showed (Figure 1c) that the majority of DNA formed dimers with AuNPs. Hence, we confirmed that the conjugates in b1 were mDNA-AuNPs, whereas b2 corresponded to the one-to-one hybridsized product of two complementary mDNA-AuNPs. Given these findings, we conclude that polyA can effectively mediate the anchoring of DNA on BSPPprotected AuNPs.

The adsorption of polyA on BSPP-protected AuNPs was much slower than that on citrate-stabilized AuNPs at near-neutral $\mathrm{pH}$ (Supplementary Figure S1a). Interestingly, we found that this process could be greatly accelerated at acidic $\mathrm{pH}$, a phenomenon similar to that in the case of thiolated DNA. ${ }^{39,40}$ To systematically investigate the $\mathrm{pH}$ effect on polyA-mediated functionalization of AuNPs, we prepared a series of buffer solutions with various $\mathrm{pH}$ values, which were mixed with the solution of DNA and AuNPs. As the presence of AuNPs in solution perturbs precise measurements of the solution $\mathrm{pH}$, the $\mathrm{pH}$ values hereafter indicate the $\mathrm{pH}$ of the buffer solutions instead of the mixed solutions. We found that a diblock DNA with 80As (polyA80) could be readily assembled on AuNPs within $15 \mathrm{~min}$ when the solution $\mathrm{pH}$ was below 4, whereas AuNPs were hardly functionalizable within a short period at $\mathrm{pH}$ 4-8 (Supplementary Figure S1b). Therefore, the low $\mathrm{pH}$-assisted assembly strategy facilitates the preparation of DNA-AuNPs without using the tedious salt-aging step.
Further analysis in the $\mathrm{pH}$ range of $2-4$ (Figure 2a and Supplementary Table S2) revealed that an extremely high yield of $\sim 90 \%$ was realized with the buffer of $\mathrm{pH} 3.1$. This nearly quantitative yield suggests that polyA80 can be 'clicked' onto AuNPs and that wrapping of polyA80 occupies the surface of AuNPs, such that the adsorption of additional DNA strands is prevented.

We next explored the length effect of polyA on DNA functionalization of AuNPs. The $\mathrm{pH}$ value of the buffer solution was fixed at the optimal level of 3.1. We used 100-base diblock DNA strands, with the length of the polyA block in the range of 10-80. Our previous studies indicated that nearly all As could be directly adsorbed onto $\mathrm{Au}$, making polyA lying flat on the AuNP surface. ${ }^{34}$ Consistently, we found that the yield of mDNA-AuNPs was improved along with the length increase when the polyA length exceeded 40, which reached a maximum of $\sim 90 \%$ with polyA80 (Figure $2 \mathrm{~b}$ and Supplementary

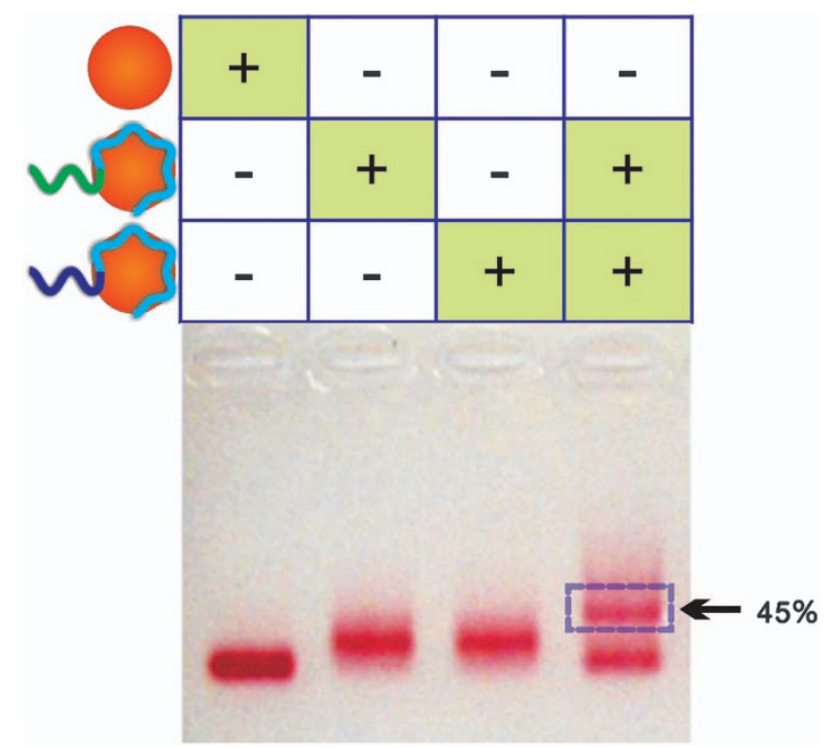

Figure $4 \mathrm{Gel}$ images for two types of unpurified mDNA-AuNPs with complementary sequences and their hybridized conjugates.
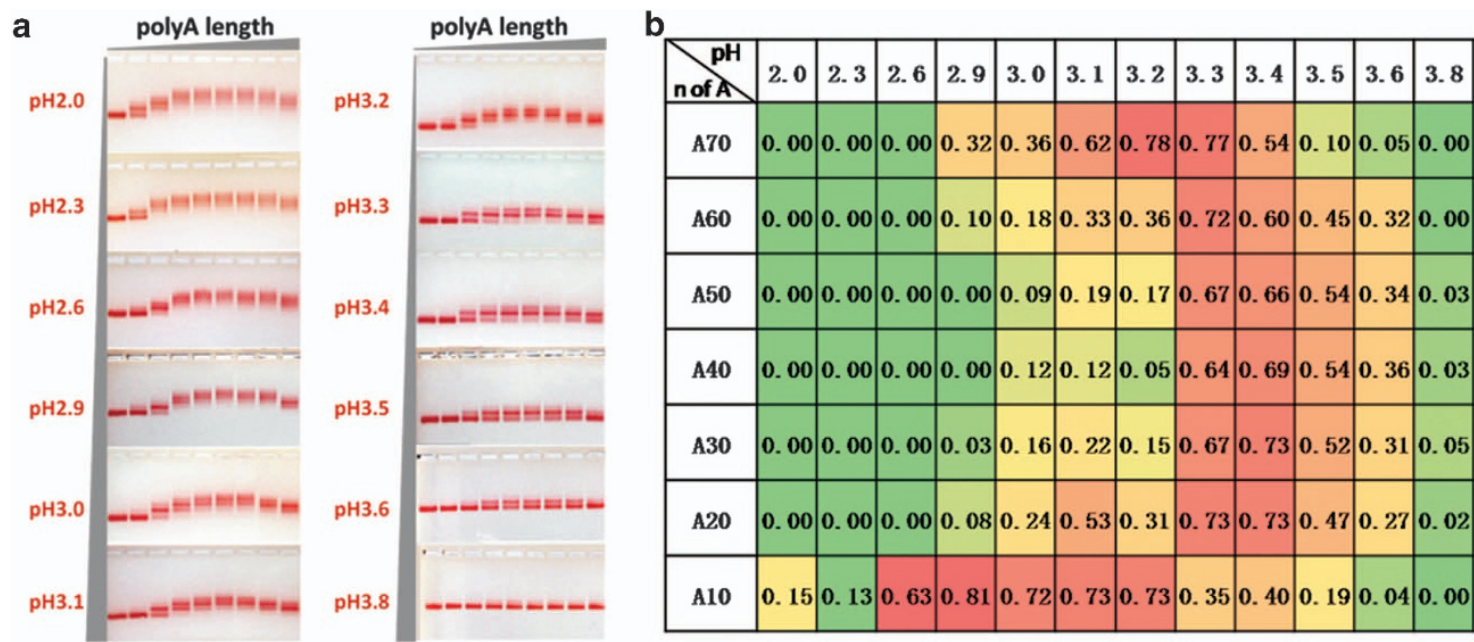

Figure 3 (a) Gel images for AuNPs treated with different polyA-DNAs (from left to right in each gel: untreated AuNPs, AuNPs treated with DNA strands containing polyAO polyA70) with different pH buffers. (b) The heat map of mDNA-AuNPs yields derived from (a). 
Table S3). Noticeably, we obtained a large portion of divalent or trivalent DNA-AuNPs with polyA of shorter lengths (40-70), suggesting that the surface occupation is the driving force for the preparation of mDNA-AuNPs. Interestingly, we also note that the synthesis yield was decreased when the polyA length was below 40 . In particular, we obtained a mDNA-AuNPs yield of $62 \%$ with polyA10, leaving 36\% of unmodified AuNPs. We ascribe this counter-intuitive phenomenon to the kinetic effect. Because this low-pH-assisted strategy is largely a kinetic process instead of the thermodynamic one for salt-aging over 1-2 days, longer polyA should have stronger tendency to bind to AuNPs with faster speed. Regardless, we conclude that low-valence DNA-AuNPs including mDNA-AuNPs can be rapidly prepared with high yields by simply varying the length of polyA.

We further studied the effect of the stoichiometric ratio between DNA and AuNPs (DNA/AuNPs) on the functionalization of polyA80 onto AuNPs. Significantly, we found that the yield of mDNA-AuNPs was insensitive to the ratio of DNA/AuNPs when the ratio exceeded one (Figure $2 \mathrm{c}$ and Supplementary Table S4). This result suggests that polyA80 provides sufficient affinity and steric hindrance to wrap the surface AuNPs, thereby preventing the adsorption of additional strands. In contrast, excess thiolated DNA tended to result in the formation of polyvalent DNA-AuNPs (Supplementary Figures S2a, b). This effect provides further evidence for the clicking nature of polyA to AuNPs, which obviates the necessity to precisely quantify the amount of DNA and AuNPs. Therefore, this polyA-mediated strategy can form mDNA-AuNPs with a nearly quantitative yield of $90 \%$.

Given that both $\mathrm{pH}$ and polyA length are two crucial factors for the preparation mDNA-AuNPs, we next performed a two-factor screening experiment to identify the optimum condition. By varying both the $\mathrm{pH}$ and polyA length, we generated a two-dimensional array to a

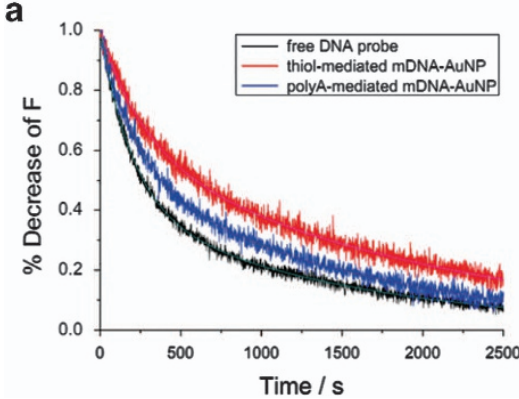

b

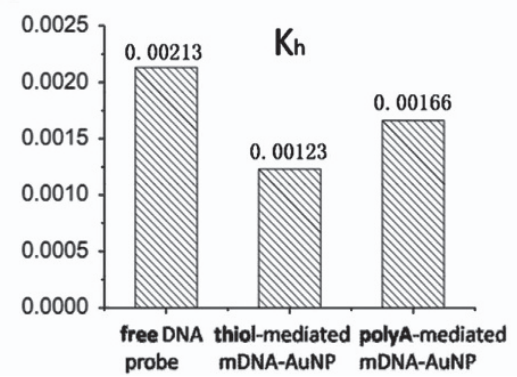

C

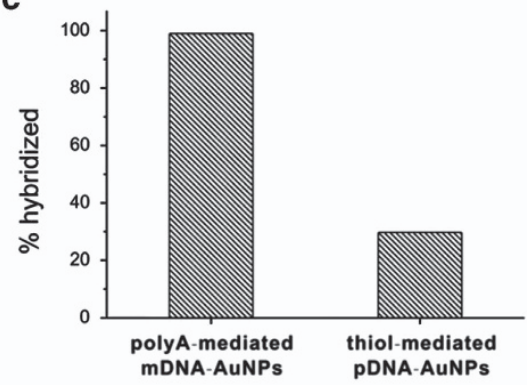

Figure 5 (a) The DNA hybridization kinetics of free DNA probes, thiol-mediated mDNA-AuNPs and polyA-mediated mDNA-AuNPs. (b) Kinetic constants derived from (a). (c) The hybridization efficiencies of probe DNAs on polyA-mediated mDNA-AuNPs and thiol-mediated pDNA-AuNPs with their target DNA.

a

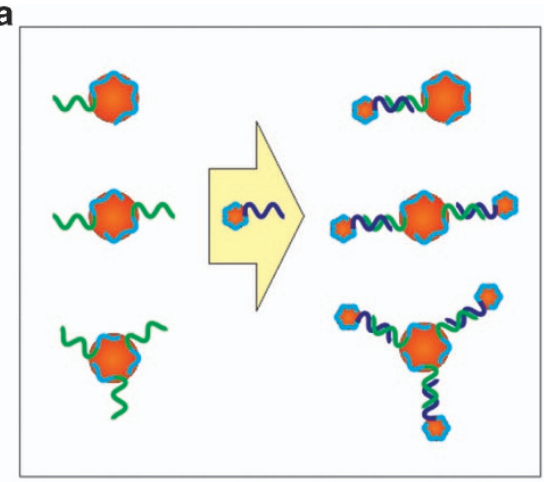

b

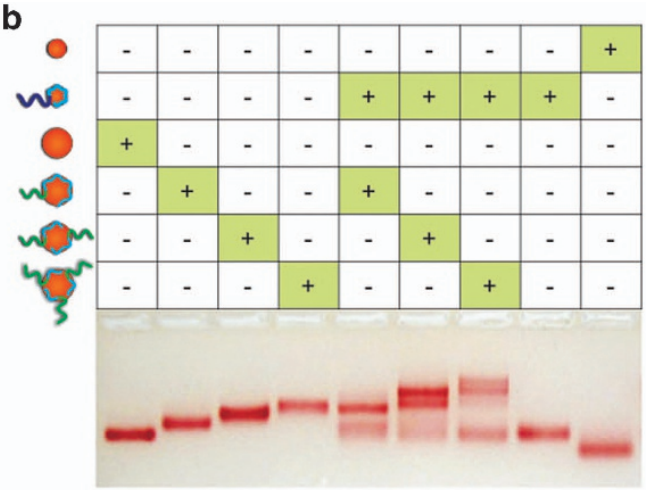

C

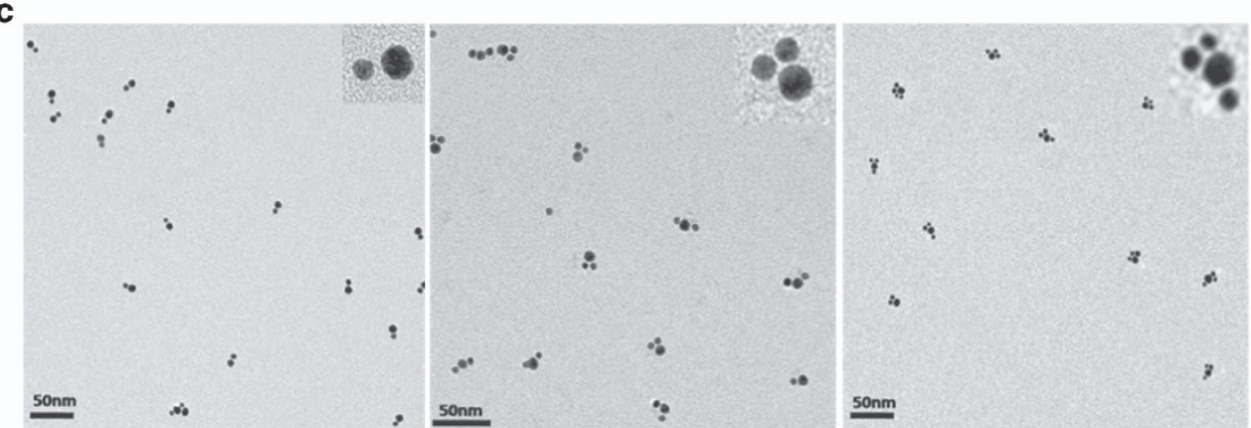

Figure 6 (a) Schematic representation showing monovalent, divalent and trivalent 10-nm DNA-AuNPs hybridized with one, two and three 5-nm mDNAAuNPs. (b) Gel images of these DNA-AuNPs and their conjugates. (c) TEM characterization of heterogenous dimers, trimers and tetramers of DNA-AuNPs (from left to right). 
demonstrate the yields of mDNA-AuNPs (Figure 3). We found that polyAs of different lengths had their own optimum $\mathrm{pH}$ values that resulted in high yields of $\sim 60-70 \%$. Importantly, compared with the yield of polyA with 10-70 bases, the combination of polyA80 and the buffer of pH 3.1 exhibits the highest yield of $90 \%$. Even unpurified mDNA-AuNPs can be directly used for further assembly of dimers. Two types of mDNA-AuNPs with complementary DNA sequences led to the formation of dimers with a yield of $\sim 45 \%$ (Figure 4 ).

Having obtained mDNA-AuNPs with high yield, we then interrogated their hybridization ability. As AuNPs are excellent quenchers for fluorescence, we used fluorophore-labeled complementary DNA strands to hybridize with mDNA-AuNPs. The fluorophore was located in the proximity of the AuNP surface after hybridization, resulting in efficient fluorescence quenching. As controls, we used thiolated DNA-mediated mAuNPs and organic quencher-labeled DNA strands. Kinetic studies indicated that hybridization on thiolmediated mDNA-AuNPs was slower than pure homogenous DNADNA hybridization by $42 \%$, whereas that on polyA-mediated ones was only $27 \%$ slower (Figures $5 \mathrm{a}$ and $\mathrm{b}$ ). This result indicates that polyAmediated mDNA-AuNPs have faster hybridization kinetics than thiolated DNA-based mDNA-AuNPs, possibly due to the different degrees of freedom of surface-confined DNA strands. We also compared the hybridization efficiency of polyA-based mDNA-AuNPs and thiolated pDNA-AuNPs ( 24 DNA strands per particle) bearing the same probe sequence. Both samples were hybridized with excessive fluorophore-labeled target DNAs for $2 \mathrm{~h}$. We found that mDNAAuNPs had a hybridization efficiency of $\sim 99 \%$, whereas only $\sim 30 \%$ of the DNA strands on pDNA-AuNPs were hybridized (Figure $5 \mathrm{c}$ ).

The availability of mDNA-AuNPs offers great potential for bottomup construction of nanostructures with high precision. To substantiate this potential, we prepared a series of building blocks comprised of mDNA-AuNPs of 10 or $5 \mathrm{~nm}$, bivalent, and trivalent DNA-AuNPs of $10 \mathrm{~nm}$ (Figures $6 \mathrm{a}$ and $\mathrm{b}$ ). The mDNA-AuNPs were prepared using the polyA-mediated click strategy described above, and bivalent and trivalent DNA-AuNPs were purified with gel electrophoresis. Using these AuNPs of fixed valences, we obtained three types of heterogenous oligomers, including dimers, trimers and tetramers, with reasonably high yields of 63,56 , and $23 \%$, respectively (Figures $6 \mathrm{~b}$ and c). Apparently, these fixed-valence DNA-AuNPs are analogous to atoms used to precisely form molecule-like nanoassemblies.

\section{CONCLUSIONS}

In summary, we demonstrated a facile and fast strategy to prepare mDNA-AuNPs using diblock polyA-DNA. Under acidic $\mathrm{pH}$, polyA can be rapidly adsorbed on AuNPs. With a polyA length of 80, DNA strands can be 'clicked' onto AuNPs with nearly quantitative yields and with insensitivity to the stoichiometric ratio of DNA/AuNPs. These polyA-mediated mDNA-AuNPs exhibited fast hybridization kinetics and high hybridization efficiency. Using DNA-AuNPs of fixed valences, we demonstrated that well-defined molecule-like nanoassemblies of heterogeneous oligomers can be readily formed. ${ }^{4,41}$ It is also envisioned that these DNA-AuNPs can be further exploited to assemble high-ordered structures, for example, hydrogel or crystals with better control and homogeneity. ${ }^{14-16}$ In addition, because we have obtained high yields of well-defined and uniform $\mathrm{Au}$ nanostructures, we expect that this system holds great promise for DNAregulated plasmonic applications ${ }^{42,43}$ and biomolecular imaging. ${ }^{44-47}$

\section{CONFLICT OF INTEREST}

The authors declare no conflict of interest.

\section{ACKNOWLEDGEMENTS}

This work was supported by the National Basic Research Program (2013CB932803, 2012CB932600 and 2013CB933802), NSFC (91313302, 21390414, 21329501) and the Chinese Academy of Sciences.

1 Mirkin, C. A., Letsinger, R. L., Mucic, R. C. \& Storhoff, J. J. A DNA-based method for rationally assembling nanoparticles into macroscopic materials. Nature $\mathbf{3 8 2}$ 607-609 (1996).

2 Alivisatos, A. P., Johnsson, K. P., Peng, X., Wilson, T. E., Loweth, C. J., Bruchez, M. P. Jr \& Schultz, P. G. Organization of 'nanocrystal molecules' using DNA. Nature 382 609-611 (1996).

3 Elghanian, R., Storhoff, J. J., Mucic, R. C., Letsinger, R. L. \& Mirkin, C. A. Selective colorimetric detection of polynucleotides based on the distance-dependent optical properties of gold nanoparticles. Science 277, 1078-1081 (1997).

4 Loweth, C. J., Caldwell, W. B., Peng, X. G., Alivisatos, A. P. \& Schultz, P. G. DNA-based assembly of gold nanocrystals. Angew. Chem. Int. Ed. 38, 1808-1812 (1999).

5 Boisselier, E. \& Astruc, D. Gold nanoparticles in nanomedicine: preparations, imaging, diagnostics, therapies and toxicity. Chem. Soc. Rev. 38, 1759-1782 (2009).

6 Giljohann, D. A., Seferos, D. S., Daniel, W. L., Massich, M. D., Patel, P. C. \& Mirkin, C. A. Gold nanoparticles for biology and medicine. Angew. Chem. Int. Ed. 49, 3280-3294 (2010)

7 Mout, R., Moyano, D. F., Rana, S. \& Rotello, V. M. Surface functionalization of nanoparticles for nanomedicine. Chem. Soc. Rev. 41, 2539-2544 (2012).

8 Lin, M. H., Pei, H., Yang, F., Fan, C. H. \& Zuo, X. L. Applications of gold nanoparticles in the detection and identification of infectious diseases and biothreats. Adv. Mater. 25, 3490-3496 (2013).

9 Busson, M. P., Rolly, B., Stout, B., Bonod, N., Larquet, E., Polman, A. \& Bidault, S. Optical and topological characterization of gold nanoparticle dimers linked by a single DNA double strand. Nano Lett. 11, 5060-5065 (2011).

10 Lan, X., Chen, Z., Liu, B. J., Ren, B., Henzie, J. \& Wang, Q. DNA-directed gold nanodimers with tunable sizes and interparticle distances and their surface plasmonic properties. Small 9, 2308-2315 (2013)

11 Sheikholeslami, S., Jun, Y. W., Jain, P. K. \& Alivisatos, A. P. Coupling of optical resonances in a compositionally asymmetric plasmonic nanoparticle dimer. Nano Lett. 10, 2655-2660 (2010).

12 Lim, D.-K., Jeon, K.-S., Kim, H. M., Nam, J.-M. \& Suh, Y. D. Nanogap-engineerable Raman-active nanodumbbells for single-molecule detection. Nat. Mater. 9 60-67 (2010).

13 Lan, X. \& Wang, Q. DNA-programmed self-assembly of photonic nanoarchitectures. NPG Asia Mater 6, e97. doi:10.1038/am.2014.16 (2014).

14 Park, S. Y., Lytton-Jean, A. K., Lee, B., Weigand, S., Schatz, G. C. \& Mirkin, C. A. DNAprogrammable nanoparticle crystallization. Nature 451, 553-556 (2008).

15 Macfarlane, R. J., Lee, B., Hill, H. D., Senesi, A. J., Seifert, S. \& Mirkin, C. A. Molecula recognition and self-assembly special feature: Assembly and organization processes in DNA-directed colloidal crystallization. Proc. Natl Acad. Sci. USA 106 10493-10498 (2009).

16 Macfarlane, R. J., O'Brien, M. N., Petrosko, S. H. \& Mirkin, C. A. Nucleic acid-modified nanostructures as programmable atom equivalents: forging a new "table of elements". Angew. Chem. Int. Ed. 52, 5688-5698 (2013).

17 Maye, M. M., Kumara, M. T., Nykypanchuk, D., Sherman, W. B. \& Gang, O. Switching binary states of nanoparticle superlattices and dimer clusters by DNA strands. Nat. Nanotechnol 5, 116-120 (2010).

18 Kumar, S. Discotic liquid crystal-nanoparticle hybrid systems. NPG Asia Mater. 6, e82. doi:10.1038/am.2013.75 (2014).

19 Nam, J. M., Stoeva, S. I. \& Mirkin, C. A. Bio-bar-code-based DNA detection with PCRlike sensitivity. J. Am. Chem. Soc. 126, 5932-5933 (2004).

20 Zhang, J., Song, S., Zhang, L., Wang, L., Wu, H., Pan, D. \& Fan, C. Sequence-specific detection of femtomolar DNA via a chronocoulometric DNA sensor (CDS): Effects of nanoparticle-mediated amplification and nanoscale control of DNA assembly at electrodes. J. Am. Chem. Soc. 128, 8575-8580 (2006).

21 Cutler, J. I., Zhang, K., Zheng, D., Auyeung, E., Prigodich, A. E. \& Mirkin, C. A. Polyvalent nucleic acid nanostructures. J. Am. Chem. Soc. 133, 9254-9257 (2011).

22 Tan, S. J., Campolongo, M. J., Luo, D. \& Cheng, W. Building plasmonic nanostructures with DNA. Nat. Nano 6, 268-276 (2011)

23 Guerrero-Martínez, A., Grzelczak, M. \& Liz-Marzán, L. M. Molecular thinking for nanoplasmonic design. ACS Nano 6, 3655-3662 (2012).

24 Zanchet, D., Micheel, C. M., Parak, W. J., Gerion, D. \& Alivisatos, A. P. Electrophoretic isolation of discrete Au nanocrystal/DNA conjugates. Nano Lett. 1, 32-35 (2001).

25 Bidault, S., de Abajo, F. J. G. \& Polman, A. Plasmon-based nanolenses assembled on a well-defined DNA template. J. Am. Chem. Soc. 130, 2750-2751 (2008).

26 Claridge, S. A., Liang, H. Y. W., Basu, S. R., Frechet, J. M. J. \& Alivisatos, A. P. Isolation of discrete nanoparticle-DNA conjugates for plasmonic applications. Nano Lett. 8, 1202-1206 (2008).

27 Suzuki, K., Hosokawa, K. \& Maeda, M. Controlling the number and positions of oligonucleotides on gold nanoparticle surfaces. J. Am. Chem. Soc. 131 7518-7519 (2009)

28 You, C. J., Wilmes, S., Beutel, O., Löchte, S., Podoplelowa, Y., Roder, F., Richter, C. Seine, T., Schaible, D., Uzé, G., Clarke, S., Pinaud, F., Dahan, M. \& Piehler, J. 
Self-controlled monofunctionalization of quantum dots for multiplexed protein tracking in live cells. Angew. Chem. Int. Ed. 49, 4108-4112 (2010).

29 Kim, J. W., Kim, J. H. \& Deaton, R. DNA-linked nanoparticle building blocks for programmable matter. Angew. Chem. Int. Ed. 50, 9185-9190 (2011).

30 Li, Z. T., Cheng, E., Huang, W., Zhang, T., Yang, Z., Liu, D. \& Tang, Z. Improving the yield of mono-DNA-functionalized gold nanoparticles through dual steric hindrance. $J$. Am. Chem. Soc. 133, 15284-15287 (2011).

31 Tikhomirov, G., Hoogland, S., Lee, P. E., Fischer, A., Sargent, E. H. \& Kelley, S. O. DNA-based programming of quantum dot valency, self-assembly and luminescence. Nat. Nanotechnol. 6, 485-490 (2011).

32 Wen, Y. Q., Chen, L., Wang, W., Xu, L., Du, H., Zhang, Z., Zhang, X. \& Song, Y. A flexible DNA modification approach towards construction of gold nanoparticle assemblies. Chem. Commun. 48, 3963-3965 (2012).

33 Farlow, J., Seo, D., Broaders, K. E., Taylor, M. J., Gartner, Z. J. \& Jun, Y. W. Formation of targeted monovalent quantum dots by steric exclusion. Nat. Methods 10, 1203-1205 (2013).

34 Pei, H., Li, F., Wan, Y., Wei, M., Liu, H., Su, Y., Chen, N., Huang, Q. \& Fan, C. Designed diblock oligonucleotide for the synthesis of spatially isolated and highly hybridizable functionalization of DNA-gold nanoparticle nanoconjugates. J. Am. Chem. Soc. 134, 11876-11879 (2012).

35 Pellegrino, T., Sperling, R. A., Alivisatos, A. P. \& Parak, W. J. Gel electrophoresis of gold-DNA nanoconjugates. J. Biomed. Biotechnol. 2007, 26796-26796 (2007).

36 Hurst, S. J., Lytton-Jean, A. K. R. \& Mirkin, C. A. Maximizing DNA loading on a range of gold nanoparticle sizes. Anal. Chem. 78, 8313-8318 (2006)

37 Aldaye, F. A. \& Sleiman, H. F. Dynamic DNA Templates for discrete gold nanoparticle assemblies: control of geometry, modularity, write/erase and structural switching. $J$. Am. Chem. Soc. 129, 4130-4131 (2007).

38 Zheng, Y. Q., Li, Y. L. \& Deng, Z. X. Silver nanoparticle-DNA bionanoconjugates bearing a discrete number of DNA ligands. Chem. Commun. 48, 6160-6162 (2012).

39 Zhang, X., Liu, B., Dave, N., Servos, M. R. \& Liu, J. Instantaneous attachment of an ultrahigh density of nonthiolated DNA to gold nanoparticles and its applications. Langmuir 28, 17053-17060 (2012).

40 Zhang, X., Servos, M. R. \& Liu, J. W. Instantaneous and quantitative functionalization of gold nanoparticles with thiolated DNA using a pH-Assisted and surfactant-free route. J. Am. Chem. Soc. 134, 7266-7269 (2012).
41 Claridge, S. A., Goh, S. L., Fréchet, J. M. J., Williams, S. C., Micheel, C. M. \& Alivisatos, A. P. Directed assembly of discrete gold nanoparticle groupings using branched DNA scaffolds. Chem. Mater. 17, 1628-1635 (2005).

42 Cheng, W. L., Campolongo, M. J., Cha, J. J., Tan, S. J., Umbach, C. C., Muller, D. A. \& Luo, D. Free-standing nanoparticle superlattice sheets controlled by DNA. Nat. Mater. 8, 519-525 (2009).

43 Cheng, W. L., Hartman, M. R., Smilgies, D. M., Long, R., Campolongo, M. J., Li, R., Sekar, K., Hui, C. Y. \& Luo, D. Probing in real time the soft crystallization of DNAcapped nanoparticles. Angew. Chem. Int. Ed. 49, 380-384 (2010).

44 Baciu, C. L., Becker, J., Janshoff, A. \& Sonnichsen, C. Protein-membrane interaction probed by single plasmonic nanoparticles. Nano Lett. 8, 1724-1728 (2008).

45 Liu, G. L., Yin, Y., Kunchakarra, S., Mukherjee, B., Gerion, D., Jett, S. D., Bear, D. G., Gray, J. W., Alivisatos, A. P., Lee, L. P. \& Chen, F. F. A nanoplasmonic molecular ruler for measuring nuclease activity and DNA footprinting. Nat. Nanotechnol. 1, 47-52 (2006).

46 Sonnichsen, C., Reinhard, B. M., Liphardt, J. \& Alivisatos, A. P. A molecular ruler based on plasmon coupling of single gold and silver nanoparticles. Nat. Biotechnol. 23 , 741-745 (2005)

47 Lim, D. K., Jeon, K. S., Hwang, J. H., Kim, H., Kwon, S., Suh, Y. D. \& Nam, J. M. Highly uniform and reproducible surface-enhanced Raman scattering from DNAtailorable nanoparticles with 1-nm interior gap. Nat. Nanotechnol. 6, 452-460 (2011).

(c) (1) (-)(2) This work is licensed under a Creative Commons Attribution-NonCommercial-ShareAlike 4.0 International License. The images or other third party material in this article are included in the article's Creative Commons license, unless indicated otherwise in the credit line; if the material is not included under the Creative Commons license, users will need to obtain permission from the license holder to reproduce the material. To view a copy of this license, visit http://creativecommons.org/licenses/ by-nc-sa/4.0/

Supplementary Information accompanies the paper on the NPG Asia Materials website (http://www.nature.com/am) 